\title{
A FIGURA IDENTITÁRIA DE ANTÔNIO CONSELHEIRO E SUAS IMPLICAÇÕES NO COTIDIANO DE CANUDOS
}

\section{Figure identity of Antônio Conselheiro and its implications for the daily life of Canudos}

\author{
Bruno Amaro Queiroz Blini ${ }^{1}$ \\ Maria Augusta de Castilho ${ }^{2}$
}

Recebido em 16/09/2015; aceito em 10/06/2016

\begin{abstract}
Resumo: A pesquisa é fruto de um estudo sobre a figura de Antônio Conselheiro e suas implicações no cotidiano de Canudos. O intuito do trabalho foi o de caracterizar de forma sistemática as principais marcas identitárias da comunidade, com o objetivo de identificar e analisar esse personagem histórico, o cotidiano do Arraial de Belo Monte e a Guerra de Canudos. O estudo se desenvolveu por meio de uma revisão bibliográfica, apoiando-se em textos de autores que tratam essa temática.
\end{abstract}

Palavras-chave: Canudos; Antônio Conselheiro; Identidade.

\begin{abstract}
The research is the result of a study of the figure of Antonio Conselheiro and its implications in everyday of Canudos. The aim of the study was to systematically characterize the main identity marks of the community, with the goal of identifying and analyzing this historical character, everyday of the Arraial de Belo Monte and the war of Canudos. The study was developed through a literature review, relying on texts by writers on this subject.
\end{abstract}

Words key: Canudos; Antônio Conselheiro. Identity.

\section{Introdução}

Este artigo é fruto de um estudo sobre a figura de Antônio Conselheiro e suas implicações no cotidiano de Canudos. O intuito do trabalho foi o de caracterizar de forma sistemática as principais marcas identitárias de Antônio Conselheiro, analisando sua figura, ressaltando também suas características de liderança, com o objetivo de alavancar e revelar o cotidiano do Arraial de Belo Monte e a Guerra de Canudos. O intuito desta pesquisa é também refletir sobre a identidade de Antônio Conselheiro e a historiografia pós-colonial para verificar como ela foi construída e suas implicações no cotidiano, sob um viés dos estudos do historiador francês Michel de Certau, via estudos voltados para o cotidiano.

\footnotetext{
${ }^{1}$ Mestrando em Educação e graduado em História pela Universidade Católica Dom Bosco.

${ }^{2}$ Doutora em História Social pela Universidade de São Paulo, com graduação em História. Atualmente é professora no Programa de Pós-graduação em Desenvolvimento Local e do Curso de História da Universidade Católica Dom Bosco - Campo Grande - MS. Email: m.a.castilho@terra.com.br.
} 
Este trabalho foi desenvolvido por meio de uma revisão bibliográfica, apoiando-se em autores que tratam à temática, tais como: Rui Facó, Ataliba Nogueira, José Calasans e Edmundo Moniz. Outros textos não menos importantes também foram usados, tais como: teses, dissertações, artigos disponíveis em portais de órgãos de pesquisa e internet. Foram priorizados os relatos sobre a identidade do Conselheiro e o cotidiano de todo o período de Canudos, desde a sua formação até a destruição de Belo Monte.

Por uma questão de organização, primeiramente, abordou-se o cotidiano do sertão e da vida de Antônio Conselheiro. Em seguida, destacou-se o surgimento do personagem histórico Antônio Conselheiro e o messianismo, bem como, o seu papel político, religioso e seus discursos messiânicos, ressaltando que essa foi a principal forma de caracterizar a sua identidade e as suas representações.

O estudo contempla também o cotidiano da população de Canudos e a influência direta que Conselheiro teve nas atividades centrais do arraial como: trabalho, economia, organização social, conflitos, entre outros. Enfatiza-se ainda o legado de Conselheiro para a história brasileira e a destruição do arraial.

\section{O cotidiano do sertão e a sua influência na formação identitária de}

\section{Antônio Conselheiro}

Para estabelecer a influência identitária de Antônio Conselheiro no cotidiano do movimento de Canudos/Belo Monte foi necessário antes de tudo fazer uma análise contextual do cotidiano do sertão nordestino a partir de 1830. Isso ocasionou um processo de argumentos de como foi construída a identidade desse líder religioso e político.

Pensar a história como um estudo do/nos/com o cotidiano, apoiando-se em Certeau (1998), significa entender e problematizar o contexto pelo viés da micro-história, rompendo assim com a visão tradicional (macro-história). Para que não sejam feitas falsas afirmações sobre o papel histórico de Antônio Conselheiro, precisa-se de uma atenção especial ao cotidiano do sertão, para assim enfatizar a sua formação identitária. Por isso, ressalta-se o cotidiano de um determinado lugar/região vinculando-o ao processo de formação de identidades naquele determinado espaço/território.

Antônio Vicente Mendes Maciel que posteriormente se tornaria o mito chamado Antônio Conselheiro, nasceu em Quixeramobim no sertão cearense. $\mathrm{O}$ ano de seu nascimento é um tanto divergente, alguns afirmam ser em 1828, outros em 1830. Mas independente do ano, sabe-se que foi nesse período que o Brasil começou a passar por um processo de grande mudança econômica e política. Em 1830, durante o período regencial, já havia uma série de 
revoltas no norte e nordeste do país. Nascer e viver em um ambiente em que a insatisfação com o modo de vida imposto começava a tomar maiores proporções afetando muito a formação identitária da população (FAUSTO, 1995).

A vida do sertanejo, além de simples e submissa, era marcada pelo trabalho semiservil além das secas. A violência dos coronéis latifundiários, que mandavam e desmandavam no sertão, fazia parte do cotidiano das famílias que lá habitavam. Um fato típico ocasionado pelos latifundiários era as brigas entre famílias, em que geralmente a família tradicional, ameaçava e reprimia as famílias de menor poderio econômico e político, como o que fizeram os Araújo, ao massacrar os Maciel (Família de Conselheiro). Essa foi iniciada em 1833 e resultou na morte do avô de Conselheiro. "As brigas de família, no sertão, tinham sempre como fatores determinantes a luta pela terra e pelo poder político" (MONIZ, 2001, p. 20). Outras influências dos coronéis no cotidiano nordestino resultaram em algumas características na sociedade como o patriarcalismo, pois, os senhores de engenho detinham todo o poder e prestígio da região.

O nordeste foi uma das partes mais afetadas por toda essa situação. Conselheiro nasceu em uma época de transição entre o sistema colonial e a economia capitalista. $\mathrm{O}$ latifúndio canavieiro do nordeste enfrentava uma grande crise, devido às mudanças econômicas, mas ainda sufocava a massa rural sertaneja. Era o que Prado Júnior (2006) chamava de evolução agrícola, que resultou em uma grande crise nos países produtores de cana, principalmente no Brasil, que usava uma técnica ainda rudimentar e atrasada.

O sistema servil estava agonizando depois de um longo período colonial. "No Nordeste, a situação agravou-se quando, na segunda metade do século XIX, o centro da gravidade econômica foi-se transferindo gradativamente para o Sul, mais desenvolvido do ponto de vista capitalista" (FACÓ, 1983, p. 17). Assim, o desenvolvimento capitalista, voltouse para o sul/sudeste e complicou ainda mais o cotidiano do sertão nordestino, que já era sofrido e abandonado. Ademais, pode-se destacar ainda que o sertanejo passava por um grande período de isolamento, em que a maioria da população não conseguia ter voz ou força alguma.

Dentre os fatores que ocasionaram o 'isolamento' das regiões nordestinas do resto da nação, cabe destacar: 1) o fato de as transformações ocorridas no sul não terem alterado substancialmente o quadro social do norte; 2) a grande distância do Distrito Federal; 3) a ausência de uma infra-estrutura adequada (escolas, atendimento médico, saneamento básico); 4) a falta de investimentos provenientes do governo federal; 5) pouca aplicação de recursos nas áreas carentes (SOLA, 1989, p. 14). 
Sabendo de todos esses fatores, como: isolamento, submissão, patriarcalismo, falta de terras para os mais pobres, exploração, cobranças de impostos, dentre outros, o cotidiano da população sertaneja ficou caracterizado pela falta de tudo. "A população que habitava os sertões vivia de forma bem mais primitiva do que a que habitava o litoral: as casas (se é que podiam ser chamadas de casas) eram construídas de barro e carnaúba, algumas mais pobres eram edificadas apenas em madeira" (SOLA, 1989, p. 15). Ainda segundo Sola, 88\% da população mal sabia ler, e a alimentação básica era somente mandioca e carne seca (quando tinha). Foi um tempo marcado pela pobreza e sofrimento, em que "os meios de transporte comuns eram os animais, o lombo do burro ou o carro de boi, que passavam por quaisquer caminhos, qualquer picada aberta no campo" (FACO, 1983, p. 43).

Além disso, os grandes períodos de secas eram algo um tanto quanto rotineiro, agravando ainda mais a situação de miséria e, consequentemente, a extrema pobreza no sertão. Houve ainda uma grande seca entre 1877 e 1879, que foi um grande divisor de águas no cotidiano do povo sertanejo. A seca de 1877 foi um período em que o sertão se ateve a dois fatores: a migração e a religiosidade (fanatismo). Dessa forma, a população, completamente abandonada e não encontrando nenhuma ajuda, começou a se apoiar na religiosidade. Era uma fé popular, ligada ao misticismo, às crendices, que tinha o objetivo de compensar a fome e a situação de carência, e não um catolicismo oficial (que estava longe da realidade dos sertanejos). Muitos buscaram esse apoio e começaram a seguir Antônio Conselheiro. Eram os chamados fanáticos que seguiam o "messias" atrás de apoio, surgindo então o chamado movimento messiânico.

Esta 'fé' adotada pelo sertanejo, na verdade nada mais é do que instinto de sobrevivência, pois ele recorre à religião como uma forma de solucionar seus problemas. Como a religião oficial não atende às suas necessidades essenciais -como a fome - através da religiosidade popular tenta suprir essa carência (SOLA, 1989, p. 18).

Outro ponto importante da época em que o sertão viveu a fase da grande seca foi: “a emigração em larga escala que se inicia com a grande seca de 1877 a 1879, a qual deixou memória em toda a região, até os dias de hoje" (FACÓ, 1983, p. 29). Os sertanejos fugiram para a região amazônica (brasileira e estrangeira), onde pretendiam esquivar-se da miséria, e partiram de qualquer modo, alguns iam até seminus, tamanha era a necessidade do povo, que tinha sido castigado pela seca e pela miséria. Lá chegaram para trabalhar nos seringais, era a época de ouro do chamado império da borracha, "Agora, atraía o migrante o surto da borracha na Amazônia" (FACÓ, 1983, p. 29). Este autor enfatiza que o êxodo foi tanto, que o governo 
cearense começou a fornecer até passagens para que os migrantes voltassem para o sertão, principalmente, nos períodos de queda de preço da borracha. Mas eles voltaram diferentes, além de armados, estavam revoltados, por verem toda a situação de progresso da região dos seringais, contrastando com a situação do sertão. Surgiram então os chamados cangaceiros, e foram formando vários grupos de cangaço espalhados pelo sertão nordestino.

Esse foi um pouco do cotidiano que Antônio Vicente Mendes Maciel viveu, além de todas as adversidades de sua vida pessoal. Ele teve uma formação religiosa no meio de muita opressão e miséria, e isso resultou em grandes traços de sua identidade. Um homem tradicional, mas com um grande entendimento político, viu sua família ser explorada, assim como a grande parte dos sertanejos, que estavam sufocados pelos impostos e pelos coronéis latifundiários.

Posteriormente, o Brasil iria passar por uma grande mudança política com o fim da monarquia e o início da república burguesa, influenciada pelos ideais iluministas. Isso afetaria diretamente um homem com uma formação tradicional religiosa, já que a república pregava a separação da igreja e do estado, instituindo o casamento civil, além de ser um movimento maçônico. Antônio Conselheiro que viveu durante esse período percebeu que, além de prejudicar a religião, a nova república com sua política capitalista em vez de desenvolver o sertão, aumentaria ainda mais o abandono do sertanejo. Percebe-se, nesse período, que o olhar republicano estava virando ainda mais para o sudeste, onde estava às fazendas de café, ocasião em que Antônio Conselheiro pregava a todos os fanáticos que a república era inimiga de Deus e dos sertanejos.

\section{0 personagem histórico Antônio Conselheiro e o messianismo}

Este item servirá para reforçar o personagem/mito histórico chamado Antônio Conselheiro, explanando também sobre o messianismo praticado por ele, seus ideais e a sua imagem. Conselheiro foi sem dúvidas um dos personagens mais místicos, conhecidos e mal compreendidos da história brasileira, e muito disso se deve a sua devoção, a sua repercussão e às divergências historiográficas sobre a sua identidade e a sua ideologia.

Os primeiros autores o descreviam sob um olhar pejorativo retratando Conselheiro como um fanático maluco. Obviamente, muitos dos escritos eram feitos sob a influência do governo republicano, como a vertente de Euclides da Cunha no clássico literário - Os Sertões. No entanto, posteriormente, surgiram alguns autores que iriam contrapor essa visão, como os marxistas: Rui Faço; Edmundo Moniz e José Calasans. Essas divergências historiográficas 
permitiram uma análise mais coerente sobre Antônio Conselheiro, inseridas na memória popular nordestina.

Antônio Vicente Mendes Maciel começa a ser tornar o personagem Antônio Conselheiro, mais especificamente quando deu início a uma vida nômade no sertão nordestino, levando uma vida messiânica. "O ambiente de religiosidade e misticismo favorecia o surgimento de beatos e messias [...]" (BANDEIRA, 2005, p. 2) e o messianismo estava diretamente relacionado com o surgimento do personagem Conselheiro, que peregrinou pelo sertão durante décadas, fazendo suas prédicas e dando os chamados conselhos para a massa pobre do sertão, e foi assim que o beato foi ganhando cada vez mais a simpatia dos sertanejos. "Os mais pobres que viviam ao relento passaram a segui-lo diariamente e compartilhar suas rezas. Mendigos, mutilados e marginalizados pela sociedade formaram o seu primeiro séquito" (SOLA, 1989, p. 25).

Ao iniciar sua vida de peregrino, Conselheiro fez promessas de construir igrejas e cemitérios no sertão nordestino. Vivendo apenas para sua subsistência, sem qualquer luxo, Conselheiro foi “[...] inquestionavelmente, o maior edificador de igrejas dos sertões da Bahia, na zona compreendida entre os rios São Francisco, Vaza-Barris e Itapicuru, por onde peregrinou durante quase um quartel de século, de 1874 a 1897” (CALASANS, 1973, p. 2). Conselheiro era uma espécie de messias para o povo e arrastava consigo cada vez mais multidões em suas peregrinações, tornando-se um verdadeiro profeta do sertão. "Por volta de 1877, ano da grande seca no Nordeste, Antônio Vicente Mendes Maciel, que como Antônio Conselheiro se notabilizaria, já peregrinava pelos sertões, a fazer e a arrastar fiéis por onde passava” (BANDEIRA, 2005, p. 2).

O número de escravos e de ex-escravos (posteriormente à Lei Áurea) que fugiram para acompanhar Conselheiro era considerável, pois eles estavam completamente desamparados pelo governo. "Sua popularidade aumentava cada vez mais e a abolição da escravatura, em 1888, concorreu para aumentar-lhe as hostes, com negros libertos, sem destino e sem ocupação, em meio de grave crise econômica" (BANDEIRA, 2005, p. 2). Um personagem que ganhou popularidade entre homens, mulheres, crianças, escravos e toda a massa excluída do sertão, que fazia de suas pregações não só um discurso religioso, mas também político e social, certamente, incomodaram muito os republicanos, parte do clero católico, os grandes fazendeiros e toda a elite.

Um dos fatores marcantes sobre a história de Antônio Conselheiro foi a sua relação com os/a republicanos/república. Conselheiro era apontado pelos republicanos como um monarquista, o que de fato faz certo sentido, mas, além disso, ele era um antirrepublicano 
declarado. Isso se deu por vários motivos, a república tinha os ideais burgueses e iluministas, defendia um estado laico e o casamento civil, o que, para um religioso tradicional como era Conselheiro, era um absurdo: “O repúdio à República por parte de Antônio Maciel funda-se, tal como demonstrado, no conflito de valores configurado com a instauração do governo leigo" (OLIVEIRA, 2000, p. 109). O fortalecimento do capitalismo que os republicanos pregavam serviu ainda mais para subjulgar a massa pobre do sertão, como por exemplo, o aumento dos impostos. "Os conselheiristas se rebelaram contra a cobrança de impostos [...] o Conselheiro manda arrancar os editais de cobrança de impostos e com eles fazer uma fogueira em praça pública" (FACO, 1983, p. 90). Com essa atitude ele tornasse uma espécie de demônio obsoleto e ultrapassado para os republicanos, no entanto, um grande messias para os sertanejos, já que o governo republicano era totalmente ausente no sertão:

Assim, essa aristocracia almejava apenas 'modernizar' o Brasil segundo seus interesses e de forma alguma pretendia defender uma reforma agrária ou a mudança profunda no quadro social do país. Por isso não é de se estranhar que a alteração política em nada mudou as condições de vida dos camponeses, principalmente no que tange ao nordeste. Lá o que mudava era apenas o nome do sistema. A estrutura social continuava a mesma: grandes extensões territoriais nas mãos de poucos e a maioria vivendo sob a égide do desemprego e da fome (SOLA, 1989, p. 30).

A relação de Antônio Conselheiro com a religiosidade, suas peregrinações messiânicas, seus seguidores, suas construções, suas ideologias e seu papel social e político, marcaram sua personalidade. Tais concepções são discutidas até hoje na história e, ainda geram muitos conflitos por parte dos estudiosos, que analisam a origem do personagem Antônio Conselheiro e a criação de Belo Monte/Canudos.

\section{O cotidiano de Belo Monte}

Depois de muitos anos de peregrinação, Conselheiro fundou em 1893 uma comunidade a qual denominou Arraial de Belo Monte, e que passou a ser conhecida como Canudos. Era uma fazenda abandonada à margem do rio Vaza-Barris, era um oásis no sertão. Depois de conhecer praticamente o sertão inteiro devido a suas andanças e pregações, Conselheiro escolhe essa região no sertão baiano para fundar a sua comunidade. O local foi sabiamente escolhido, por causa de sua localização estratégica, indicando que ele já previa grandes represálias contra seu povo e a sua comunidade. 
Antônio Conselheiro fundara, em 1893, o arraial de Monte Belo, celebrizado como Canudos, em que agremiava não apenas baianos, senão caboclos oriundos de todos os Estados limítrofes, desde o tabaréu crendeiro ao cangaceiro remido do crime pela religião de acordo com princípios igualitários [...] (BANDEIRA, 2005, p. 9).

O que mais chamou atenção em Belo Monte foi sua localização isolada e de difícil acesso, com um clima adverso para quem viesse de fora. "O relevo era mais um obstáculo a ser vencido e se constituía no principal elemento de defesa contra as futuras investidas do exército republicano" (SOLA, 1989, p. 36), além de estar cercado por cinco serras: Canabrava, Cocorobó, Cambaio, Calumbi e Caipã e por vários rios (ver figura 1 a seguir).

Figura 1 - Localização de Canudos

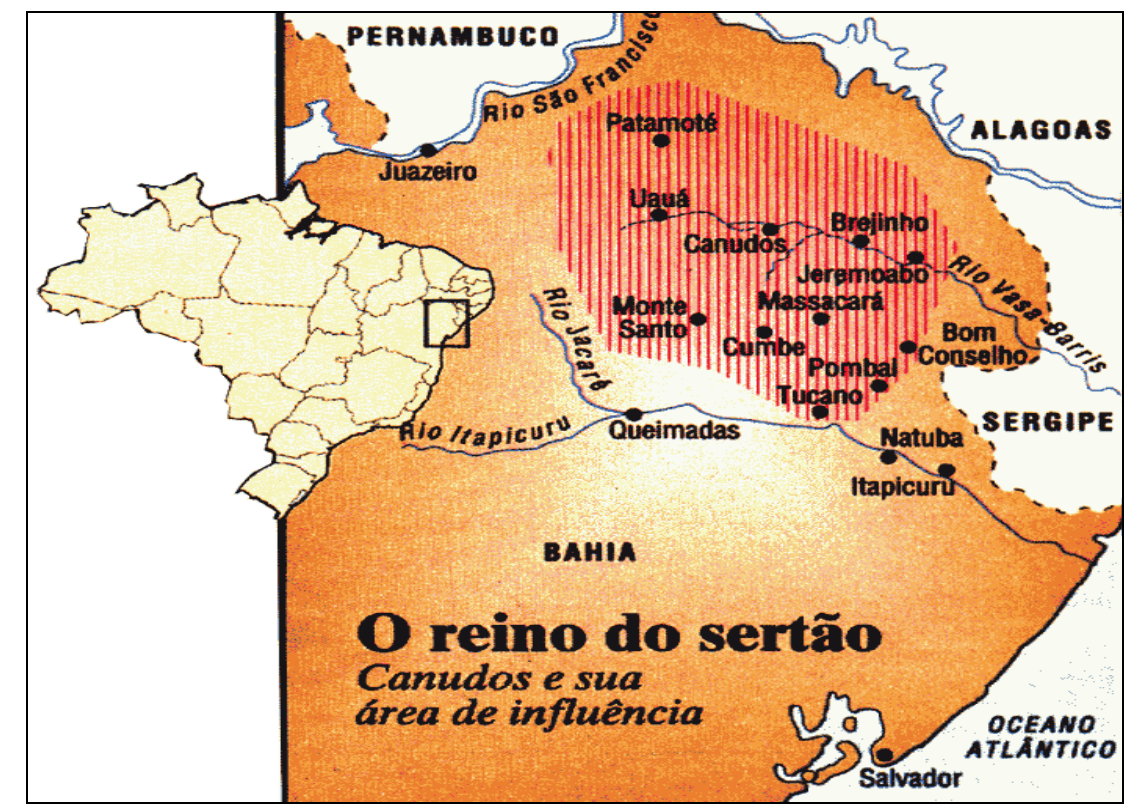

Fonte: Disponível em <http://jografia.blogspot.com.br/2014/03/canudos-e-sua-areade-influencia.html>. Acesso em: 13 abr. 2014.

Belo Monte era uma comunidade simples, os habitantes viviam com o mínimo de luxo (algo que já era comum para os sertanejos). O dia-a-dia na comunidade era marcado também pelas festividades, com direito a muitos fogos (os foguetórios), rezas, músicas, práticas comuns nas festas do arraial (Canudos). Apesar de toda simplicidade na vida em comunidade, Belo Monte apresentou algumas peculiaridades tanto em suas características, quanto no seu cotidiano em termos de organização. A começar pelas casas, que eram verdadeiras taperas de pau-a-pique (casas feitas de barro), de um cômodo, verdadeiros casebres "[...] mais de 5 mil casas espalhadas sem alinhamento sobre uma série de colinas de grande significado estratégico" (FACÓ, 1983, p. 100). Embora vivessem dessa forma, todos 
os sertanejos lá existentes tinham o que comer, pois plantavam, criavam animais e todo o trabalho era dividido da seguinte forma: os mais jovens com serviços mais pesados, idosos e mulheres com serviços mais leves, como alimentar e zelar das criações e colher frutos. Por isso, ninguém detinha excessos, mas também não ficava na miséria.

O cotidiano de Canudos era simples e bem organizado, todos tinham alguma função e as regras tinham de ser seguidas, era tudo planejado por Conselheiro e seus homens de confiança. "O álcool era proibido, pois além de viciar os habitantes poderia gerar brigas e desentendimentos" (SOLA, 1989, p. 39), o consumo de álcool pelos sertanejos era muito comum, mas a população acatava bem as ordens de Conselheiro.

A comunidade tinha a sua própria guarda, a segurança tinha seus homens de frente, “[...] Pajeú, um José Venâncio, um João Abade [...] Eles integravam a chamada guardacatólica ou santa companhia, instituição mantida pelos recursos da própria comunidade, para a defesa do Conselheiro e sua cidadela" (CALAZANS, 1970, p. 8). Pajeú era o grande guerreiro, o principal chefe da guarda e dos combates na guerra, protegia Canudos e lutou como poucos contra as investidas republicanas. Era um homem de extrema confiança de Conselheiro. Já as investigações internas do arraial ficavam a cargo de Antônio Beato, o beatinho, o principal braço direito de Conselheiro (FACÓ, 1983).

Devido a toda essa organização, aumentava absurdamente o número de pessoas no arraial. Outro fato era a pluralidade de pessoas existentes em Canudos, gente do sertão inteiro, desamparada pelo governo, tais como: mulheres, cangaceiros, crianças e velhos. Existia a rua dos caboclos, dos negros, dos aleijados, dos doentes mentais, enfim todos foram para Canudos sob a proteção de Conselheiro. Não existiam mendigos e prostitutas, ou se existiam, ao entrar em Canudos deixavam de ser. A população também era composta (em menor número) por pessoas com melhores situações financeiras e política, que segundo Calasans (1974), Marciano de Sergipe que lutou heroicamente nas batalhas e era parente do coronel Siqueira Menezes.

Era uma sociedade de extremo preceito religioso e bem tradicional como era seu líder maior, porém, menos rígida que a Igreja Católica, detendo-se mais nos conselhos do que no julgamento de seus seguidores. Belo Monte tinha a sua rotina: como a hora dos conselhos e das prédicas de Conselheiro, em que todos se reuniam para ouvi-lo e no domingo descansava-se. "[...] o Conselheiro falava sobre os mandamentos, condenava os pecados, aconselhava para o bem, citando, não raro, frases latinas. Depois da proclamação da República, porém, as questões políticas foram entrando no desenvolvimento de suas falações" (CALASANS, 1974, p. 18). As prédicas de Conselheiro, algo muito comum no cotidiano de 
Belo Monte, foi tão importante que Ataliba Nogueira dedicou boa parte do seu livro sobre Antônio Conselheiro e Canudos, as suas prédicas. Baseando-se nelas, percebe-se a ideologia de Conselheiro e suas características, vendo que o objetivo maior era o religioso. Também enfatizava os mandamentos bíblicos, sobre a importância da missa, a comunhão, entre outras atividades. No entanto, em algumas prédicas havia um viés mais político e filosófico, principalmente, no momento em que a república começou a persegui-los e combatê-los.

Outros três temas marcaram intensamente o cotidiano de Canudos, merecendo aqui um destaque especial, as mulheres, os jagunços e a guerra. Os dois primeiros tiveram uma extrema relevância para o último (a guerra). As mulheres de Belo Monte foram tão importantes, que mereceriam um trabalho exclusivo sobre a história delas (como fez Udinéia Braga), em Belo Monte, “[...] o mulherio constituía a parte mais numerosa dos fanáticos que seguiam para Canudos, chegando a cerca de dois terços dos vinte e seis mil habitantes que compunham o arraial" (BRAGA, 2011, p. 7). A importância dessas mulheres na sociedade era enorme, desde os momentos das rezas, quanto nos momentos da colheita, pois, produziam artesanato e ainda lutaram com extrema coragem na guerra, participando ativamente das batalhas, pegando em armas, ajudando maridos, filhos e a todos do arraial. Em uma guerra em que a cidade atacada possuía em sua maioria mulheres e, mesmo assim, as tropas republicanas tiveram diversos reveses, considerando a força dessas mulheres em lutar pela sua comunidade e pelo seu povo.

Os jagunços também foram personagens importantes para Canudos. Considerado homem símbolo do sertão nordestino, vítima do descaso do governo, encontrou em Belo Monte um verdadeiro abrigo e o defendeu até o fim. Lutar para os jagunços era algo que eles faziam em suas vidas no sertão, ainda semicolonial e não era nada fácil. Eram homens que faziam a guarda de pessoas, e também estavam ligados ao termo capanga, no entanto, foram muitos deles que venderam ou deixaram as suas posses e bens para ir para Canudos. "O jagunço de Canudos foi um brasileiro esquecido, desamparado, injustiçado, que encontrou amparo espiritual e, muitas vezes, ajuda material no singular peregrino que afirmava ir aonde os desventurados, os chamassem e que eram milhares nos sertões brasileiros da segunda metade do século passado" (CALASANS, 1970). Como a maioria dos personagens, os jagunços foram marginalizados pelos escritores da época, no entanto, os escritores como Calasans e Facó trouxeram outra visão do que eles verdadeiramente representaram para a comunidade e vice e versa.

A guerra e os combates de Canudos, mesmo não sendo o foco deste trabalho, necessitam de uma atenção, pois é praticamente impossível analisar o cotidiano de Belo 
Monte, sem retratar ao menos em parte os combates e as represálias à comunidade. Durante muito tempo, e até o seu fim, o cotidiano de Belo Monte foi marcado pelos combates das forças republicanas contra o povo de Conselheiro, e isso representou um impacto muito grande na sociedade. $\mathrm{O}$ episódio da madeira ficou conhecido como um marco para o início da guerra. Conselheiro comprou madeira dos Irmãos Evangelistas em Juazeiro para fazer a cobertura da igreja que estava construindo em Belo Monte, mas a madeira não lhe foi entregue, e Conselheiro avisou aos Evangelistas que iria buscar a madeira, em Juazeiro. Nessa ocasião espalharam a notícia de que Conselheiro e seu povo iriam saquear a cidade, o que não era verdade, mas isso foi usado como um pretexto para o ataque inicial aos canudenses (NOGUEIRA, 1974).

Ao todo foram quatro grandes batalhas, que durou cerca de um ano e deixaram centenas de mortos e feridos. As forças governistas encontraram muitas dificuldades, pois os sertanejos praticavam táticas de guerrilhas, usavam trincheiras, além de muito ódio e vontade de defender o seu espaço. Destaca-se também a importância de Pajeú pela força de combate e Antônio Fogueteiro, um aliciador de combates, usando fogos para que os sertanejos nunca fossem pegos de surpresa (FACO, 1983). Os sertanejos estavam levando vantagem em todos os combates, mesmo em número menor e sem o armamento adequado (usavam até foices e machados) como o do exército, e muitos “[...] sertanejos ainda continuavam a chegar a Canudos, ao tempo em que a quarta expedição iniciava suas operações, sob incessante ataque de guerrilhas" (BANDEIRA, 2005, p. 17). A quarta foi à expedição derradeira, em que o exército ainda teve de contar com mais um reforço, (que alguns autores chamam de quinta expedição) que contou com um reforço de mais de 3000 homens e vários canhões, um verdadeiro derramamento de sangue. Mas um fato é certo, a fidelidade e a garra dos sertanejos para defender a sua comunidade foi algo que pouco se viu na história brasileira (SOLA, 1989).

\section{$4 \mathrm{O}$ fim de Antônio Conselheiro, Belo Monte e seus legados}

O criador de Belo Monte morreu antes do final da guerra contra os canudenses e alguns autores afirmam que o falecimento aconteceu no dia 22 de agosto, outros no dia 22 de setembro de 1897. Antônio Conselheiro “[...] para consternação geral, faleceu [...], deixando um vazio que jamais seria preenchido. Entre as inúmeras doenças apontadas como causa de sua morte, as mais prováveis foram: [...] tuberculose, disenteria e parada cardíaca" (SOLA, 1989, p. 73). A versão de que Antonio Conselheiro foi morto pelo exército não condiz com o fato histórico real. A população de Canudos continuou lutando depois da morte de seu líder, 
confiante em milagres que poderiam acontecer. Os restos mortais de Conselheiro, após a guerra, foram retirados pelos vencedores e, ainda teve a cabeça degolada (FACO, 1983).

Outro momento importante registrado foi a despedida de Antônio Conselheiro, escrita em sua última prédica:

Adeus povo, adeus aves, adeus árvores, adeus campos, aceitai a minha despedida, que bem demonstra as gratas recordações que levo de vós, que jamais se apagarão da lembrança deste peregrino, que aspira ansiosamente a vossa salvação e o bem da Igreja. Praza aos céus que tão ardente desejo seja correspondido com aquela conversão sincera que tanto deve cativar o vosso afeto (NOGUEIRA, 1974, p. 182).

No início de outubro de 1897, Belo Monte vive seus momentos finais. "No dia 6, depois que uma comissão verificou a existência de cinco mil e duzentas casas, a cidade foi destruída a fogo e a dinamite. Tudo deveria ser destruído" (MONIZ, 2001, p. 89). Os sertanejos lutaram até o fim e não lhes foi poupada nenhuma alma, a comunidade deixa a vida para entrar para a história. Cerca de um ano de intensos combates, um dos casos de maior resistência da história brasileira, serviu para mostrar o abandono da maioria da população brasileira naquele período, um grito de basta no sertão nordestino que deixou muitas histórias. Assim, Belo Monte entra para a história brasileira, por meio da chamada Guerra de Canudos, que colocou frente a frente o exército brasileiro contra a massa explorada, que nesse local encontrou abrigo e amparo. “A epopeia de Canudos ficará na história brasileira como um patrimônio das massas do campo e uma glória do movimento revolucionário pela sua libertação" (FACÓ, 1983, p. 126).

Antônio Conselheiro e a sua comunidade deixaram vários legados para a história e para a sociedade brasileira, suas ideias defendiam mudanças nos campos: social, político e religioso, que vigorava até então no Brasil, colocando em evidência as necessidades da massa pobre nordestina, que estavam à margem da sociedade da época, sem nenhuma perspectiva, e sem um olhar do governo republicano. Canudos representou uma luta de libertação dos pobres do campo, ou seja, Conselheiro e a Guerra de Canudos significaram sem dúvida um marco na história brasileira, servindo de espelho para outros movimentos camponeses (FACO, 1983).

Um dos principais legados de Conselheiro deu-se na esfera religiosa, pois a igreja estava distante dos sertanejos.

A inserção do Conselheiro no cotidiano do sertão está relacionada com os vazios deixados pela Igreja nos sertões. Essas populações vivendo em precárias condições materiais, sem apoio institucional, viam-se, também, abandonadas pela religião, predominantemente da tradição católica. Os fiéis encontravam-se sem qualquer assistência religiosa [...] (OLIVEIRA, 2000, p. 23). 
Conselheiro de certa forma preencheu esses vazios deixados pela igreja, usando de palavras de apoio e consolo em seus discursos, mostrando que a igreja deveria estar mais perto de seus fiéis.

Outro ponto a ser destacado foi a representação que Conselheiro e Belo Monte tiveram para o sertão após o término da guerra. As chamas de Canudos influenciaram o sertão, e a partir de seus momentos finais, surge Padre Cícero, que foi o grande líder depois da morte de Antônio Conselheiro. Os movimentos populares armados no sertão ainda continuaram, espalhando-se por outras áreas. Sem dúvida, Antônio Conselheiro, Belo Monte e a Guerra de Canudos, foi um ponto primordial para que eclodissem novas insatisfações da massa pobre no sertão nordestino (FACO, 1983).

\section{Considerações finais}

Os acontecimentos retratados neste artigo mostram o cotidiano turbulento do sertão nordestino, na metade final do século XIX, fruto da ausência republicana com a massa pobre que lá vivia. Antônio Conselheiro, um homem religioso de uma educação tradicional, acolheu os necessitados, dando-lhes apoio social e espiritual. As construções de igrejas e cemitérios, as secas, as prédicas, as festas e foguetórios, as repressões, fizeram parte do cotidiano de Conselheiro e da comunidade local que vivia em Belo Monte.

A pesquisa trouxe uma abordagem apontando não apenas os personagens principais, mas também todos os que fizeram parte da história Guerra de Canudos. Percebe-se que foi um acontecimento muito bem orquestrado e de união de toda massa explorada, inclusive com a participação de mulheres, ex-escravos, idosos e crianças. Abordar o fim do criador (Conselheiro), e da criação (Belo Monte), e apontar alguns de seus legados, foi sem dúvida uma forma de mostrar o valor que a figura identitária de Antônio Conselheiro teve não só no cotidiano de Canudos, mas para a história brasileira.

Identificou-se no estudo que Antonio Conselheiro foi um dos personagens mais marcantes do sertão nordestino, resistindo ao potencial revolucionário existente no âmago dos sertanejos. Pode-se afirmar que Canudos no contexto da história brasileira, foi um patrimônio da população rural que lutou pela sua libertação.

Essa população morreu combatendo o inimigo, enfrentando as forças armadas com o objetivo de exterminá-los. O exército saiu vitorioso, mas a população agreste de Canudos nos sertões da Bahia, por meio de suas investidas, mostrou que a classe dominante estava com o estado de espírito bastante alarmado. 
Os habitantes do local tinham uma vida dura, precisavam ser homens práticos, em contato com o agreste nordestino e também pensavam na salvação da alma que os conduziriam ao céu. Ao lutarem com o exército brasileiro desejam exterminá-lo para que pudessem sobreviver e ter uma vida digna.

Canudos desaparece, pois foi totalmente alagada pela construção de uma hidrelétrica no local, mas mesmo assim sua história não foi apagada. 


\section{Referências}

BANDEIRA, Luiz Alberto Muniz. O sentido social e o contexto político da guerra de Canudos. Revista Espaço Acadêmico, Maringá, n. 50, Ano V, 2005.

BRAGA, Udinéia. Canudos: uma guerra muitas mulheres. In: Anais.... XXVI SIMPÓSIO NACIONAL DE HISTÓRIA - ANPUH. São Paulo, 2011.

CALASANS, José. Antônio Conselheiro, construtor de igrejas e cemitérios. Revista Brasileira de Cultura, ano 5, n. 16, p. 1-18, 1973.

CALASANS, José. Canudos: origem e desenvolvimento de um arraial messiânico. Salvador, 1974.

CALASANS, José. Os jagunços de Canudos. In: Anais... ARQUIVO DO ESTADO DA BAHIA, Salvador, v. 39, 1970.

CERTEAU, Michel de. A invenção do cotidiano: a arte de fazer. 3. ed. Petrópolis: Vozes, 1998.

FACÓ, Rui. Cangaceiros e fanáticos. 7. ed. Rio de Janeiro: Civilização Brasileira, 1983.

FAUSTO, Boris. História do Brasil. São Paulo: Edusp, 1995.

MONIZ, Edmundo. Canudos: a luta pela terra. 9. ed. São Paulo: Global, 2001.

NOGUEIRA, Ataliba. Antônio Conselheiro e Canudos. São Paulo: Nacional, v. 355, 1974 (Coleção Brasiliana).

OLIVEIRA, Wálney da Costa. Sertão virado do avesso - a República na região de Canudos. Dissertação (Mestrado em História) - Universidade Federal da Bahia, Salvador, 2000.

PRADO JUNIOR, Caio. História econômica do Brasil. São Paulo: Brasiliense, 2006.

SOLA, José Antonio. Canudos - uma utopia no Sertão. São Paulo: Contexto, 1989. 